\title{
Assessment of Endotoxin Removal from Reclaimed Wastewater Using Coagulation-Flocculation
}

\author{
M. Guizani' ${ }^{1}$ M. A. Lopez Zavala², N. Funamizu1 ${ }^{1}$ \\ ${ }^{1}$ Faculty of Engineering, Environmental Engineering Division, Hokkaido University, Sapporo, Japan \\ ${ }^{2}$ Water Center for Latinamerica and the Caribbean, Tecnologico de Monterrey, Monterrey, Mexico \\ Email: g_mokh@yahoo.fr, miganloza@itesm.mx,funamizu@eng.hokudai.ac.jp
}

Received 27 June 2016; accepted 11 August 2016; published 15 August 2016

Copyright (C) 2016 by authors and Scientific Research Publishing Inc.

This work is licensed under the Creative Commons Attribution International License (CC BY). http://creativecommons.org/licenses/by/4.0/

(c) (i) Open Access

\section{Abstract}

Following biological treatment, wastewater continues to have endotoxic active materials. However, because there is a trend of potable reuse and because endotoxic active materials potentially have harmful effects on human health, their removal from water is crucial. Lipopolysaccharide endotoxin has hydrophobic groups, and their removal using a coagulation-flocculation alternative is believed to be efficient. Thus, their removal from reclaimed wastewater using the coagulationflocculation process was assessed. Secondary effluent samples from a wastewater treatment plant located in Sapporo, Japan, were investigated. It was found that this process gave satisfactory results in removing endotoxins, with an optimum removal rate of up to $40.5 \%$. The endotoxin removal was maximized by adjusting the $\mathrm{pH}$ at the low range $4-5.5$, with an aluminum sulfate dose of $80 \mathrm{mg} / \mathrm{L}$. Further increases of the coagulant dose did not improve the removal efficiency. DOC and turbidity removal were at their optimum at higher $\mathrm{pH}$ range $5.5-6.5$. Thus coagulation and flocculation could be considered as the first barrier and should be followed by other treatments to safely reuse reclaimed wastewater.

\section{Keywords}

LPS Endotoxins, Wastewater, Coagulation-Flocculation, Potable Reuse

\section{Introduction}

Potable reuse of reclaimed wastewater is emerging as an alternative to alleviate stresses on conventional fresh-

How to cite this paper: Guizani, M., Lopez Zavala, M.A. and Funamizu, N. (2016) Assessment of Endotoxin Removal from Reclaimed Wastewater Using Coagulation-Flocculation. Journal of Water Resource and Protection, 8, 855-864. 
water resources and augment potable water supply. Nowadays, we count several potable reuse plants treating wastewater to a potable level. Reliance on potable reuse is expected to grow in coming years. Moreover, groundwater recharge using reclaimed wastewater has become a widespread practice around the globe [1] [2]. With the popularization of potable reuse and groundwater recharge using reclaimed wastewater, the risks associated with ingestion of treated wastewater increase. Hence, in order to ensure public safety, potable reuse plants adopt a multi-barrier approach where an integrated system of procedures, processes and tools collectively controls contaminants from passing to water supply chain. In addition, thousands of tests are performed daily to validate the treatment. Even though these colossal efforts, risks are not prevented. Indeed, potable reuse plants are not designed to treat all chemicals found in water. Lipopolysaccharide Endotoxins (LPS) are among the chemicals of concern. These are outer membrane cell wall components of most Gram-Negative Bacteria (GNB) and some cyanobacteria and they are known as pyrogens [3]-[5]. These LPS endotoxins are ubiquitous in aqueous environments and are found in large amounts in reclaimed wastewater because they are released during biological reactions and feature low biodegradability [6] [7]. LPS endotoxins are complex molecules ranging from a few kilos Daltons to hundreds of kilos Daltons in size and are composed of three main regions: lipid A, core polysaccharide, and $\mathrm{O}$ antigens [8]. LPS Endotoxin evokes a wide variety of pathophysiological reactions, including endotoxin shock, tissue injury, and death [9]. Indeed, if injected into the blood stream, LPS causes a broad range of negative health effects, including fever, asthma, exothermic inflammation, and hypotension that contribute to organ failure or death [10] [11]. Hence, parenteral and medical devices are strictly controlled to preserve human health [12]. Other routes of exposure include LPS endotoxin inhalation (air contaminated with endotoxins), such as in cotton fields, agricultural fields, fiberglass workshops and in wastewater treatment plants. Several studies correlate asthma with the LPS endotoxin presence in air [13]-[17]. LPS endotoxin ingestion is another potential exposure route, especially with the increasing interest in the potable reuse of the reclaimed wastewater, which is found to contain high levels of LPS endotoxins. LPS endotoxin ingestion is not yet well documented in the literature. However, few researchers reported that an amount of the ingested LPS endotoxin could be adsorbed by intestinal-epithelial cells and then detected in mice blood [18] [19]. Ghoshal 2009 estimated that up to $0.25 \%$ of the ingested endotoxin could be detected in blood. Humans are constantly exposed to LPS endotoxin found in drinking water, food, oral and intestinal bacteria and air among others. If today LPS endotoxins absorbed by the intestines do not threaten human health, it may not continue to be safe in the case of potable reuse. Indeed, it is reported that reclaimed wastewater shows extremely high concentration levels of endotoxins [6] [7] [20] [21]. It should be noticed that an amount of $1 \mathrm{ug} / \mathrm{Kg}$ in blood is enough to cause significant systemic inflammation in human [22]. From this perspective, LPS endotoxin has become an emerging contaminant of significant concern in reclaimed water. In wastewater treatment plants, LPS endotoxin is generated during a biological reaction [6]. These chemicals are uncontrollable at the source nor during treatment, and therefore post treatments are required. Moreover, LPS endotoxins can be considered to be temperature and $\mathrm{pH}$ stable, making their removal as one of the most difficult and challenging problems [23] [24]. Several techniques were tested for LPS endotoxin removal from reclaimed wastewater. These alternatives have been reviewed by Guizani et al. [25]. One common technique used for removing endotoxin contaminants uses membrane ultrafiltration taking advantage of the different sizes of the endotoxin and water [21] [26]. However, Kimura et al. [27] claim that severe irreversible membrane fouling is caused by polysaccharides fractions, rendering LPS endotoxin removal by ultrafilters a challenging task. Soil aquifer treatment was also tested for LPS endotoxin removal and gave satisfactory results [20]. However, its treatment efficiency was not stable over time.

Several other removal techniques such as affinity adsorbents, anionic-exchange chromatography, gel filtration chromatography, and Triton X-114 phase separation among others were employed to remove LPS endotoxin form biological preparations [28]. However, all these techniques are not cost effective in water treatment sector. Since LPS endotoxin removal from reclaimed wastewater has not yet been resolved satisfactorily, it is mandatory to investigate other methods for LPS endotoxin removal taking into consideration the properties of these chemicals. The LPS endotoxin chemicals are amphiphilic molecules containing both hydrophobic and hydrophilic groups [29]. The hydrophobic character of these chemicals is used to form large groups and aggregates to promote their settling and therefore their removal from water [30]. In addition, several researchers [31]-[33] associated the biologic activity of LPS endotoxin (e.g., toxicity) to the Lipid A. The lipid A has a net negative charge (-) and therefore the LPS endotoxins can be easily attracted to positively charged particles of coagulants and produce compact flocs suitable for easy removal by either settlement. Thus, coagulation flocculation, a common wastewater treatment alternative, is being evaluated for its efficiency in removing endotoxins from 
reclaimed wastewater. The optimum conditions that insure a better removal are discussed. The ultimate objective of this study is to assess LPS endotoxin removal from reclaimed wastewater using coagulation flocculation process and find optimum conditions for their removal in terms of initial $\mathrm{pH}$ and aluminum sulfate dose.

\section{Materials and Methods}

\subsection{Samples}

Spot samples from the secondary effluent were collected from the settling tank (secondary treatment) of the activated sludge-operated wastewater treatment plant in Sapporo, Japan. The samples were immediately transported to the laboratory, and their characteristics were examined and recorded without delay. The assays were performed in triplicate, and average values are presented. Table 1 summarizes the characteristics of the collected water samples from the secondary effluent of the activated sludge-operated treatment plant.

\subsection{Coagulation-Flocculation test}

Jar test experiments were performed to assess turbidity, DOC and LPS endotoxin removal as well as coagulation-flocculation kinetics at various $\mathrm{pH}$ values. The secondary effluent water samples were placed in a variable speed ZR4-6 jar test device (SuidoKikoKiasha ltd.), and their $\mathrm{pH}$ was adjusted from 4.5 to 8.5 (at an increment of 1 ) using either $0.1 \mathrm{M}$ sodium hydroxide $(\mathrm{NaOH})$ or $0.1 \mathrm{M}$ hydrochloridric acid $(\mathrm{HCl})$. According to Pernitsky and Edzwald (2006), favorable $\mathrm{pH}$ conditions for alum coagulation generally occur between a $\mathrm{pH}$ of 5.8 - 6.5. Then, these samples were subjected to the Coagulation-flocculation (CF) test. Aluminum sulfate, a common coagulant and a preferred reagent with several advantages, including high efficiency at low doses, low cost, low toxicity and ease of availability, was used. The test was performed in a 1-liter beaker at ambient temperature by varying the aluminum sulfate content and $\mathrm{pH}$ values (other parameters including rapid mixing speed and mixing time were kept constant). A change of one variable at a time was adopted in this study. First, at a given dose, a wide range of $\mathrm{pH}$ values was covered. From this test the optimum $\mathrm{pH}$ value for the best LPS endotoxin removal was obtained. The second test involved the variation of coagulant dose while setting the $\mathrm{pH}$ at its optimum value obtained from the previous test. As explained earlier, $\mathrm{pH}$ was adjusted using sodium hydroxide and hydrochloridric acid. The samples were tested using the following sequence: 60 seconds of rapid mixing at $110 \mathrm{rpm}$ to enhance coagulation, followed by 30 minutes of slow mixing at $25 \mathrm{rpm}$ to favor flocculation, and 30 minutes for settling. These operating conditions were selected randomly. Several coagulation test sets were conducted at different $\mathrm{pH}$ values, as mentioned above. The considered operating conditions are summarized in Table 2. For the sake of simplicity, the initial turbidity and initial endotoxin concentration effects as well as the mixing speed and time are outside the scope of this paper.

To assess the treatment efficiency, the samples were analyzed before and after the Coagulation-flocculation process. The water turbidity and DOC were measured in a HACH spectrophotometer, using a HACH kit according to the method 10173 of the HACH water analysis book (HACH, 2001) [34]. The LAL end point chromogenic assay was used to quantify the endotoxins in water samples from coagulation flocculation tests.

\subsection{Endotoxin Determination Using the LAL assay}

The LAL end point chromogenic assay using a general purpose colorimeter was used to quantify the endotoxins (Anonymous, 2006). A standard curve was established using a negative control of depyrogenated water (Et. and

\begin{tabular}{|c|c|c|}
\hline Parameters & Average value & Standard deviation \\
\hline LPS Endotoxin (EU/ml) & 1490 & 131 \\
\hline Dissolved Organic Carbon DOC (mg/L) & 21 & 1.2 \\
\hline Turbidity (NTU) & 12.9 & 0.6 \\
\hline Electric conductivity EC $(\mu \mathrm{s} / \mathrm{cm})$ & 749 & 69 \\
\hline
\end{tabular}


Table 2. Operating conditions considered in this study.

\begin{tabular}{cc}
\hline Parameters & Values \\
\hline Rapid mixing (rpm) & 110 \\
Rapid mixing times (seconds) & 60 \\
aluminum sulfate doses (mg/L) & $20,40,80$ and 250 \\
$\mathrm{pH}$ & $4.5,5.5,6.5,7.5,8.5$ \\
\hline
\end{tabular}

beta glucan free) and CSE at endotoxin activities of 1, 0.1, 0.025 and $0.00625 \mathrm{EU} / \mathrm{ml}$. The samples were incubated with the LAL reagent at $37^{\circ} \mathrm{C}$. A general purpose spectrophotometer was used to measure the absorbance at $405 \mathrm{~nm}$. Because absorbance is related to endotoxin activity, the endotoxin activity in the unknown sample was determined by comparison to the standard curve. To validate the readings, positive controls spiked with 0.1 $\mathrm{EU} / \mathrm{ml}$ of endotoxins were used to determine the recovery ratio. The spike recovery ratio for each sample must be between $50 \%$ and $200 \%$ to demonstrate a range of insignificant interference and to determine the appropriate sample dilutions. To prevent the $\mathrm{pH}$ interference during the LAL assay, TrisHCl buffer was used to maintain the $\mathrm{pH}$ at approximately 6 .

The total endotoxin activities, DOC and turbidity of water samples, before and after coagulation tests, were measured in triplicates.

\subsection{Reagents}

An endospecy ES 24 reagent kit for the chromogenic assay of endotoxin was purchased from the SEIKAGAKU Corporation, Japan. The kit consists of a lysate of Limulus Polyphemus (LAL reagent) and a synthetic chromogenic substrate, a buffer solution to dissolve the LAL reagent and depyrogenated water ( $\beta$-glucan free). The control standard endotoxin (CSE, 90 EU/vial), Pyrocolor Diazo reagent (for use with the endospecy ES 24 kit), and the LAL reagent water were purchased from the Associates of Cape Cod, Inc.

\subsection{Glassware}

Depyrogenated glass dilution and reaction tubes and depyrogenated pipette tips were purchased from SEIKAGAKU Corporation, Japan. Other glassware items were washed, rinsed with depyrogenated water, and finally, heat treated for 120 minutes at $250^{\circ} \mathrm{C}$ or above.

\section{Results}

\subsection{LPS Endotoxin Measurement Validation}

LPS endotoxin measurements were validated using a spike test. In this test a sample with a known LPS endotoxin is spiked with a known amount of LPS endotoxin. To valid the LAL test the percentage of spike recovered should be between $50 \%$ and $200 \%$. This validation indicates that there is no interference (enhancement or inhibition) from test samples. In this study, after the appropriate dilutions, the recovery of endotoxin-spiked samples for the LPS endotoxin detection, using the LAL assay, ranged from $50 \%$ to $200 \%$. This validates the LAL assay for the tested samples in this work.

\subsection{Dosed Water pH Adjustment}

The $\mathrm{pH}$ value is an important parameter in determining effective coagulation. Hence, the $\mathrm{pH}$ of samples was adjusted from 4.5 to 8.5 (at an increment of 1 ) then coagulant was added. It is worth mentioning, that the solution $\mathrm{pH}$ value decreased in all cases as a function of the aluminum sulfate dose addition. Figure 1 illustrates the effect of varying the coagulant dose on $\mathrm{pH}$ for each initial $\mathrm{pH}$ value. From this figure we can determine the target $\mathrm{pH}$ value of the solution after addition of coagulant dose.

\subsection{Optimum pH for Endotoxin Removal}

The effect of the initial $\mathrm{pH}$ on endotoxin removal is discussed in this paragraph. The coagulant dose was fixed at 


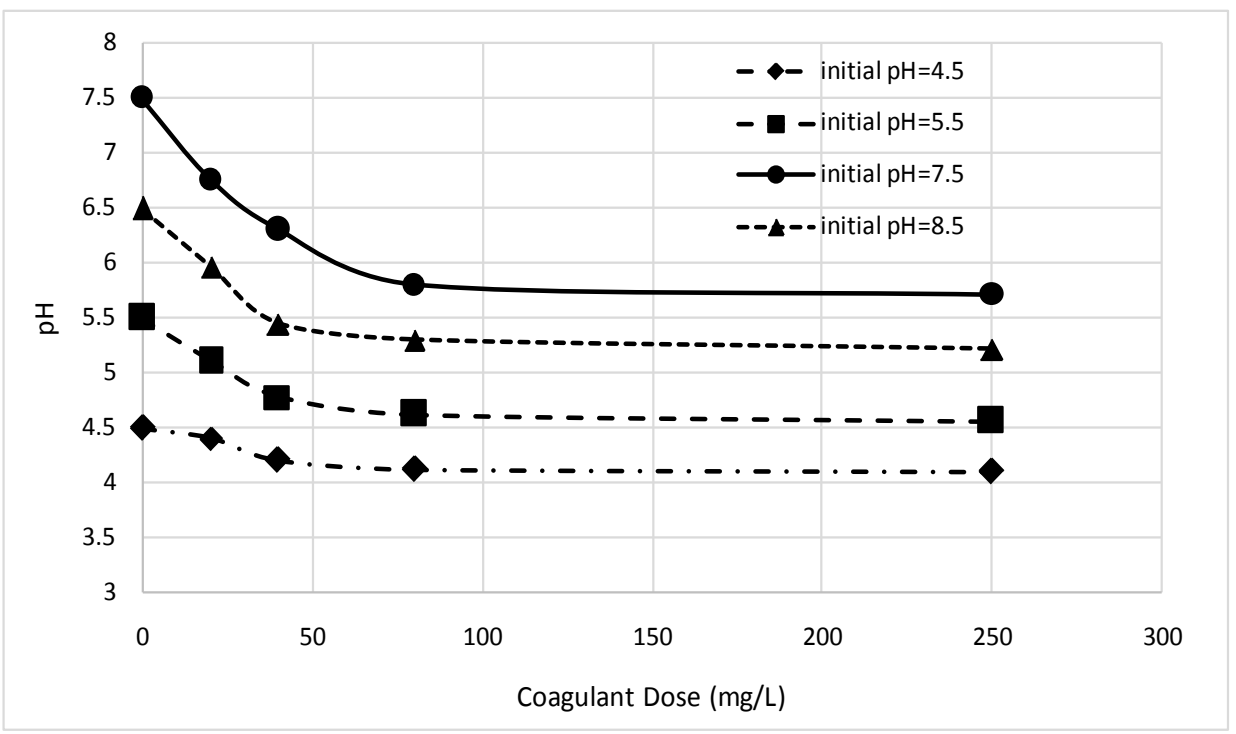

Figure 1. $\mathrm{pH}$ change in a solution (with a preset $\mathrm{pH}$ ) as a function of aluminum sulfate dose.

$80 \mathrm{mg} / \mathrm{L}$. During the experiments it was observed that the LPS endotoxin, DOC concentrations and turbidity decreased during the laboratory CF test. The average DOC concentration prior to the CF test was equal to $21 \mathrm{mg} / \mathrm{l}$ (the average of triplicate measurements). The endotoxin concentration was equal to $1490 \mathrm{EU} / \mathrm{ml}$ (average). The average effluent DOC concentrations at the end of the CF test were $11.3 \mathrm{mg} / \mathrm{l}, 8.9 \mathrm{mg} / \mathrm{l}, 9.8 \mathrm{mg} / \mathrm{l}, 10.5 \mathrm{mg} / \mathrm{l}$, and $11.2 \mathrm{mg} / \mathrm{l}$ for $\mathrm{pH}$ values stabilized at 4.13, 4.63, 5.3, 5.8 and 6.35 after coagulant addition, respectively. As shown in Figure 2, the corresponding average removal was $46.2 \%, 57.7 \%, 53.3 \%, 50 \%$ and $46.7 \%$ for pH values of 4.13, 4.63, 5.3, 5.8 and 6.35, respectively. The average effluent LPS endotoxin concentrations at the end of the CF test were $885.5 \mathrm{EU} / \mathrm{ml}, 887 \mathrm{EU} / \mathrm{ml}, 885.1 \mathrm{EU} / \mathrm{ml}, 912 \mathrm{EU} / \mathrm{ml}$ and $946.3 \mathrm{EU} / \mathrm{ml}$ for $\mathrm{pH}$ values of 4.13, $4.63,5.3,5.8$ and 6.35, respectively. The corresponding average removal was $40.6 \%, 40.4 \%, 40.6 \%, 38.8 \%$ and $36.5 \%$ for $\mathrm{pH}$ values of 4.13, 4.63, 5.3, 5.8 and 6.35, respectively (Figure 2). The turbidity decreased from $12.9 \mathrm{NTU}$ before the test to $5.63 \mathrm{NTU}, 4.32 \mathrm{NTU}, 3.57 \mathrm{NTU}, 4.72 \mathrm{NTU}$ and $4.66 \mathrm{NTU}$ for $\mathrm{pH}$ values of $4.13,4.63$, 5.3, 5.8 and 6.35, respectively. The corresponding average removal was $56.4 \%, 66.5 \%, 72.4 \%, 63.4 \%$ and $63.9 \%$ for $\mathrm{pH}$ values of 4.13, 4.63, 5.3, 5.8 and 6.35 (Figure 2).

It is worth mentioning that the percentage of endotoxin removal was at its highest values at lower $\mathrm{pH}(4-5.5)$. The optimum LPS endotoxin removal was achieved at a $\mathrm{pH}$ of 5.3 , when $40.6 \%$ of the endotoxin was removed (Figure 2). A further increase of $\mathrm{pH}$ did not improve the removal efficiencies. Rather, the efficiency gradually dropped at a higher $\mathrm{pH}$. Generally, coagulation is achieved in different ways. At higher $\mathrm{pH}(>6)$, negatively charged species dominate and entrapment is the main mechanism of removal. In this case, aluminum hydroxide $\left(\mathrm{Al}(\mathrm{OH})_{2}\right)$ precipitates forming flocs that tend to capture suspended solids as it settles out of suspension. At a lower $\mathrm{pH}(<6)$, positively charged species start to exist in the solution and dominate at a lower $\mathrm{pH}(4-5)$ and the metal ions $\left(\mathrm{Al}^{3+}\right)$ directly neutralize the negatively charged LPS endotoxin. Because of the relatively high dose of aluminum used in this case $(80 \mathrm{mg} / \mathrm{L})$, the neutralization and entrapment contribute simultaneously to the removal of LPS endotoxin at low $\mathrm{pH}$ resulting in a relatively good removal efficiency (40.6\%).

However, a different trend was observed for the DOC and turbidity removal. The optimum $\mathrm{pH}$ for DOC and turbidity removal is 5.8 and 6.35 , respectively. This suggests that the main removal mechanism is entrapment as negatively charged species dominates in this range of $\mathrm{pH}$. The turbidity removal ranged from $72.6 \%$ to $83.2 \%$, and the DOC removal varied from $45 \%$ to $57.3 \%$. The best $\mathrm{pH}$ value for the turbidity and DOC endotoxin is in the range of 5.8 to 6.35, while the best $\mathrm{pH}$ value for LPS endotoxin removal is rather in the low $\mathrm{pH}$ zone (4.3 5.3) (Figure 2). Our findings confirm the previously reported results in the literature with respect to the DOC removal in cold water (15 degree Celsius) with an approximate removal percentage of 50\%. It should be noticed that that the coagulation test in this study was conducted during the cold Sapporo season and the water temperature was in the range of 14 to 17 degree Celcius. 


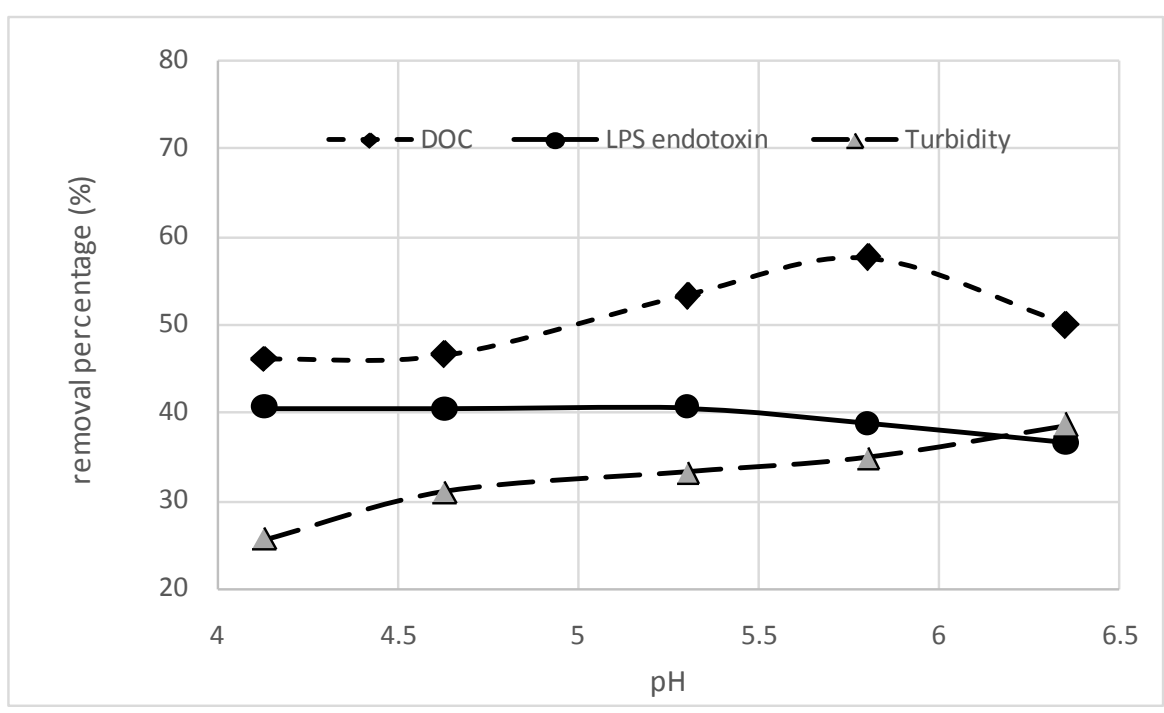

Figure 2. Removal of LPS endotoxin, DOC and turbidity vs. pH (aluminum sulfate dose: $80 \mathrm{mg} / \mathrm{L})$.

\subsection{Effect of Coagulant Dosage}

The coagulant dose effect on the endotoxic active material removal is summarized in this paragraph. The samples were flocculated using $20 \mathrm{mg} / \mathrm{L}, 40 \mathrm{mg} / \mathrm{L}, 80 \mathrm{mg} / \mathrm{L}$ and $250 \mathrm{mg} / \mathrm{L}$ aluminum sulfate doses. Since the highest LPS endotoxin removal was observed in the $\mathrm{pH}$ range 4 - 5.5, the optimization of aluminum sulfate dosage was performed by adjusting sample $\mathrm{pH}$ to 5.5 while varying the alum dosage from $20-250 \mathrm{mg} / \mathrm{L}$. As shown in Figure 1, after addition of coagulant the $\mathrm{pH}$ will drop but remains in the range of 4 - 5.5. In addition, for comparison, the data will be presented for the samples with their $\mathrm{pH}$ values adjusted to a higher value $(\mathrm{pH}=8$ before coagulant addition). During the experiment, it is observed that no or a very low number of flocks are formed at the lower coagulant doses (20 mg/L and $40 \mathrm{mg} / \mathrm{L})$. At the highest coagulant dose $(250 \mathrm{mg} / \mathrm{L})$, a large number of flocks are observed. However, at the dose of $80 \mathrm{mg} / \mathrm{L}$ the number of flock is much higher than the case of 250 $\mathrm{mg} / \mathrm{L}$ dose. Figure 3 illustrates the well-defined trends of endotoxin removal, versus the aluminum sulfate dose. It indicates that an alum dosage of $80 \mathrm{mg} \cdot \mathrm{L}^{-1}$ (as $\mathrm{Al}^{3+}$ ) resulted in the lowest residual LPS endotoxin. This dosage reduced the $\mathrm{pH}$ from 5.5 to 4.69 which favored sweep flocculation through the formation of aluminum hydroxide precipitates [35]. Further, the isoelectric point of alum occurs at $\mathrm{pH} 8$ indicating that $\mathrm{pH}$ values less than 8 yield positively charged precipitates, which are able to neutralize the negatively charged particles in the water sample [36]. At a pH stabilized at 4.69 after $80 \mathrm{mg} / \mathrm{L}$ coagulant addition, the LPS endotoxin decreased from $1490 \mathrm{EU} / \mathrm{ml}$ to $538 \mathrm{EU} / \mathrm{ml}$ corresponding to an average removal percentage of 40.5 At a higher $\mathrm{pH}$ value $(\mathrm{pH}=$ 8 before coagulant addition), a similar shape of the LPS endotoxin removal rate curve is observed but with a lower efficiency. The highest efficiency was observed again at $80 \mathrm{mg} / \mathrm{L}$ aluminum sulfate dosage and reached $36.5 \%$. It is to be notice that this dosage reduces $\mathrm{pH}$ from 7.5 to 6.35 .

Comparable shapes of removal percentage curves were observed for DOC and turbidity removal (Figure 4 and Figure 5). However the best removal at $80 \mathrm{mg} / \mathrm{L}$ coagulant dosage were observed for a $\mathrm{pH}$ of 6.35 (after coagulant addition), validating the findings related to optimum $\mathrm{pH}$ discussed earlier.

It is to be noticed that increasing the aluminum sulfate dosage is not in favor of turbidity removal. In some cases we found that at higher doses of aluminum sulfate $(250 \mathrm{mg} / \mathrm{L})$ were often observed to add turbidity to the water (Figure 4). Turbidity removal is considered to be an important parameter because turbid matter may provide good protection for bacteria. Furthermore, in the presence of trace amount of organic matter the bacteria regrowth will lead to an increase of the LPS endotoxin after the CF process. Thus, the lower residual water turbidity is the target to better control endotoxins.

\section{Discussion}

The process of coagulation/flocculation produced satisfactory results as an alternative for removing endotoxins. 


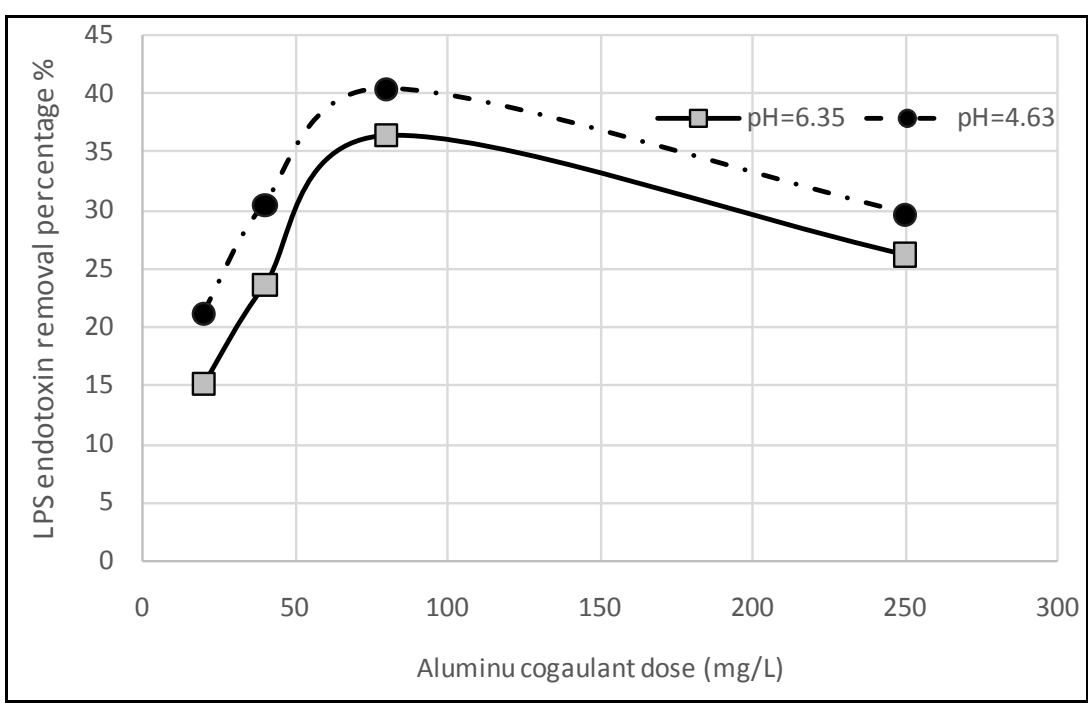

Figure 3. Removal of LPS endotoxin vs. aluminum sulfate dose (pH: 4.63 and 6.35).

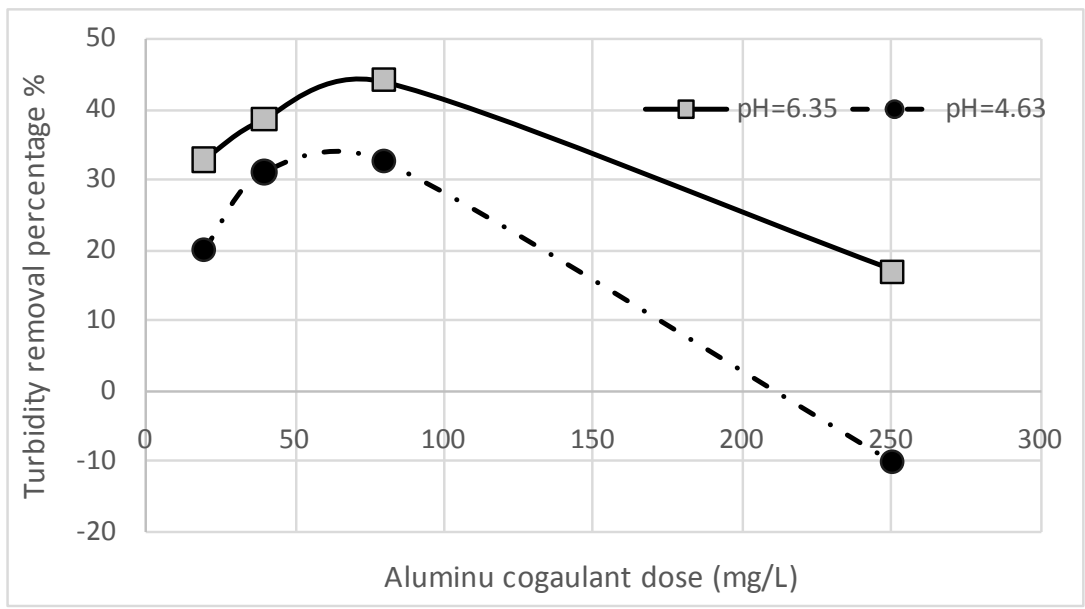

Figure 4. Turbidity vs. the aluminum sulfate dose (pH: 4.63 and 6.35).

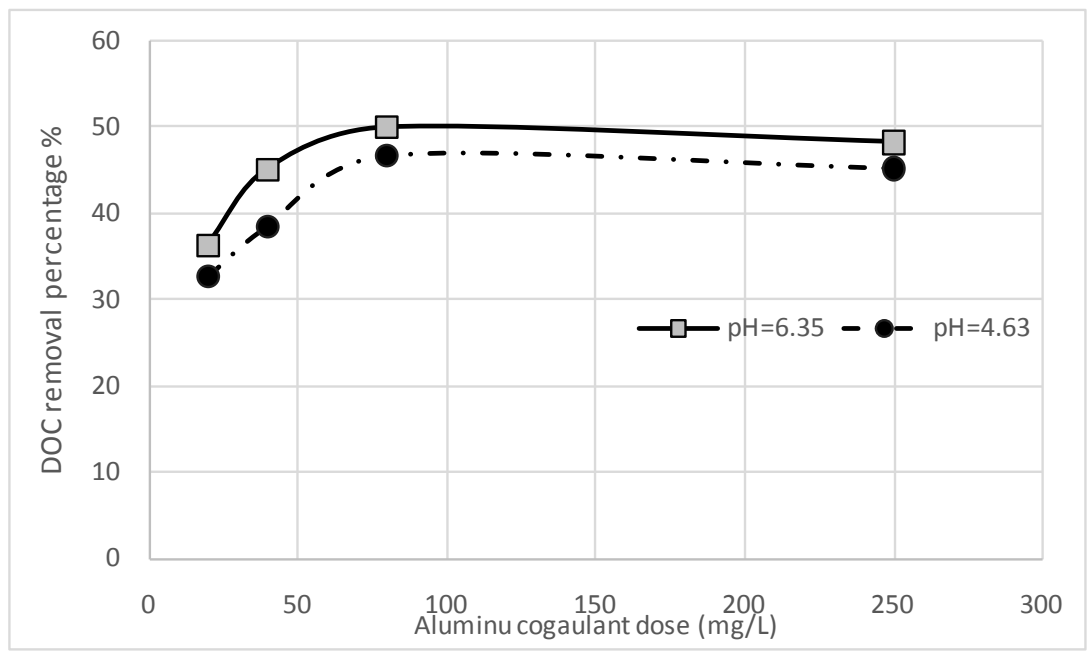

Figure 5. DOC removal vs. aluminum sulfate dose (pH: 4.63 and 6.35). 
The LPS endotoxin removal using the coagulation flocculation process achieved satisfactory but not excellent results, with up to $40.5 \%$ LPS endotoxin removal at its highest efficiency. The LPS endotoxin concentration in the supernatant of the coagulation flocculation process was found to be significantly higher than the values reported for tap water and groundwater (Anderson et al., 2002). Without standards, further treatments are required to meet the current LPS endotoxin levels in tap water and groundwater. Hence, CF is an effective first barrier to reduce endotoxins in the reclaimed wastewater.

In comparison with other treatment alternatives (e.g., sand filtration, membrane filtration, oxidation and UV treatment), coagulation flocculation is less efficient but is still an attractive cheap and affordable method. Indeed, the soil filtration approach reported by Guizani et al. in 2011 exhibited a good removal efficiency (75.6\%), but with high instability in time. However, the process is not recommended for the shallow aquifer application. Indeed, long soil columns are required for better efficiency $(90 \mathrm{~cm})$. The nano-filtration and reverse osmosis methods have a removal efficiency of more than 90\% [21]. However, these alternatives are expensive. The oxidation and UV treatments were tested only for water that was contaminated with endotoxins, other than wastewater and secondary-treated effluents. These methods are not appealing because their efficiency did not exceed $40 \%$, although the relatively low endotxicity initially present in these waters [37]. Coagulation-flocculation is a cheap and interesting alternative for reducing endotoxicity in the treated wastewater. It can be combined with other treatment options to achieve the best removal efficiency. However, with the common trend of potable reuse, the higher coagulant dose is of concern. In addition, as optimum turbidity and LPs endotoxin could not be achieved under the same conditions. The low turbidity removal at the optimum $\mathrm{pH}$ for LPS endotoxin removal, may lead to the bacterial regrowth and LPS endotoxin regeneration, which is a concern. Moreover, it is worth mentioning that this study, which is based on one variable variation at a time, provided us with optimum settings for $\mathrm{pH}$ and coagulant dose for better endotoxin removal. Rapid mixing speed and mixing time were set randomly. However, these two parameters may affect significantly the efficiency of coagulation flocculation process as they provide the interaction speed and time between molecules and particles in the water and a coagulant [38]-[40]. Hence, the influence of rapid mixing velocity and rapid mixing time will be investigated in future studies. In addition, the optimum conditions can better estimate if all possible cases are tested, which is, practically, impossible. Thus, an optimization technique that uses statistical methods, such as response surface methodology, is of interest [41].

\section{Conclusion}

Potable reuse of reclaimed wastewater is becoming a worldwide common trend. Hence efficient removal of potential contaminants found in reclaimed water is of great concern. LPS endotoxins are among the emerging contaminants of concern. In this study, taking advantage of their net negative charge and hydrophobic character, the removal of LPS endotoxin from reclaimed wastewater has been assessed using coagulation flocculation test with the use of aluminum sulfate as coagulant. The coagulation and flocculation process provided satisfactory results in reducing LPS endotoxins in water as a first barrier. The highest endotoxin removal was achieved at an aluminum sulfate dose of $80 \mathrm{mg} / \mathrm{L}$ at a $\mathrm{pH}$ of 4.69 . However, the optimum $\mathrm{pH}$ for DOC and turbidity removal was 6.35. The residual LPS endotoxin concentration was significantly higher than the reported value in tap and groundwater. This suggests a need for further treatments for safe potable reuse. Furthermore, even though there is a significant reduction of DOC and turbidity, the remaining turbid matter presents a risk of LPS endotoxin release following the bacteria regrowth. To prevent bacteria regrowth, further treatments are essential. Briefly, the CF process is a satisfactory first barrier for LPS endotoxin removal treatment.

\section{Acknowledgements}

The authors gratefully acknowledge the financial support from the Japan Society for the Promotion of Sciences (JSPS) for the first author, who conducted this research when he was a visiting scholar as an International Research Fellow.

\section{References}

[1] El Ayni, F., Cherif, S., Jrad, A. and Trabelsi-Ayadi, M. (2011) Impact of Treated Wastewater Reuse on Agriculture and Aquifer Recharge in a Coastal Area: Korba Case Study. Water Resources Management, 25, 2251-2265.

http://dx.doi.org/10.1007/s11269-011-9805-2 
[2] Scherberg, J., Baker, T., Selker, J.S. and Henry, R. (2014) Design of Managed Aquifer Recharge for Agricultural and Ecological Water Supply Assessed through Numerical Modeling. Water Resources Management, 28, 4971-4984. http://dx.doi.org/10.1007/s11269-014-0780-2

[3] Anderson, W.B., Slawson, R.M. and Mayfield, C.I. (2002) A Review of Drinking-Water-Associated Endotoxin, Including Potential Routes of Human Exposure. Canadian Journal of Microbiology, 48, 567-587. http://dx.doi.org/10.1139/w02-061

[4] Stewart, I., Schluter, P.J. and Shaw, G.R. (2006) Cyanobacterial Lipopolysaccharides and Human Health: A Review. Environmental Health, 5, 7. http://dx.doi.org/10.1186/1476-069x-5-7

[5] Williams, L.K. (2007) Endotoxins: Pyrogens, LAL Testing and Depyrogenation (Chap.4: Endotoxin Structure, Function and Activity). 3rd Edition, CRC, Indiana.

[6] Guizani, M., Dhahbi, M. and Funamizu, N. (2009) Assessment of Endotoxin Activity in Wastewater Treatment Plants. Journal of Environmental Monitoring, 11, 1421-1427. http://dx.doi.org/10.1039/b901879d

[7] Guizani, M., Dhahbi, M. and Funamizu, N. (2009) Survey on LPS Endotoxin in Rejected Water from Sludge Treatment Facility. Journal of Environmental Monitoring, 11, 1935-1941. http://dx.doi.org/10.1039/b911165d

[8] Gehr, R., Parent Uribe, S., Da Silva Baptista, I.F. and Mazer, B. (2008) Concentrations of Endotoxins in Waters around the Island of Montreal, and Treatment Options. Water Quality Research Journal of Canada, 43, 291-303.

[9] Oigikubo, Y., Ogikubo, Y., Norimatsu, M., Noda, K., Takahashi, J., Inotsume, M., Tsuchiya, M. and Tamura, Y. (2004) Evaluation of the Bacterial Endotoxin Test for Quantification of Endotoxin Contamination of Porcine Vaccines. Biologicals, 32, 88-93. http://dx.doi.org/10.1016/j.biologicals.2004.05.001

[10] Erridge, C., Bennett-Guerrero, E. and Poxton, I.R. (2002) Structure and Function of Lipopolysaccharides. Microbes and Infection, 4, 837-851. http://dx.doi.org/10.1016/S1286-4579(02)01604-0

[11] Calvano, J.E., Lowry, S.F., et al. (2003) Modulation of the Lipopolysaccharide Receptor Complex (CD14, TLR4, MD-2) and Toll-Like Receptor 2 in Systemic Inflammatory Response Syndrome-Positive Patients with and without Infection: Relationship to Tolerance. Shock, 20, 415-419. http://dx.doi.org/10.1097/01.shk.0000092269.01859.44

[12] FDA (1987) Guideline on Validation of the Limulus ameobocyte Lysate Test as an End-Product Endotoxin Test for Human and Animal Parenteral Drugs, Biological Products, and Medical Devices. US Department of Health and Human Services, Rockville, 208-257.

[13] Kennedy, S.M., Christiani, D.C., Eisen, E.A., Wegman, D.H., Greaves, I.A., Olenchock, S.A., Ye, T.-T. and Lu, P.L. (1987) Cotton Dust and Endotoxin Exposure-Response Relationships in Cotton Textile Workers. The American Review of Respiratory Disease, 135, 194-200.

[14] Schwartz, D.A., Thorne, P.S., Yagla, S.J., Burmeister, L.F., Olenchock, S.A., Watt, J.L. and Quinn, T.J. (1995) The Role of Endotoxin in Grain Dust-Induced Lung Disease. American Journal of Respiratory and Critical Care Medicine, 152, 603-608. http://dx.doi.org/10.1164/ajrccm.152.2.7633714

[15] Milton, D., Wypij, D., Kriebel, D., Walters, M., Hammond, S. and Evans, J. (1996) Endotoxin Exposure-Response in a Fiberglass Manufacturing Facility. American Journal of Industrial Medicine, 29, 3-13. http://dx.doi.org/10.1002/(SICI)1097-0274(199601)29:1<3::AID-AJIM2>3.0.CO;2-V

[16] Nightingale, J.A., Rogers, D.F., Hart, L.A., Kharitonov, S.A., Chung, K.F. and Barnes, P.J. (1998) Effect of Inhaled Endotoxin on Induced Sputum in Normal, Atopic, and Atopic Asthmatic Subjects. Thorax, 53, 563-571. http://dx.doi.org/10.1136/thx.53.7.563

[17] Thorn, J. (2001) The Inflammatory Response in Humans after Inhalation of Bacterial Endotoxin. Journal of Inflammation Research, 50, 254-261. http://dx.doi.org/10.1007/s000110050751

[18] Ghoshal, S., Witta, J., Zhong, J., de Villiers, W. and Eckhardt, E. (2009) Chylomicrons Promote Intestinal Absorption of Lipopolysaccharides. The Journal of Lipid Research, 50, 90-97. http://dx.doi.org/10.1194/jlr.M800156-JLR200

[19] Erridge, C., Attina, T., Spickett, C.M. and Webb, D.J. (2007) A High-Fat Meal Induces Low-Grade Endotoxemia: Evidence of a Novel Mechanism of Postprandial Inflammation. The American Journal of Clinical Nutrition, 86, 12861292.

[20] Guizani, M., kato, H. and Funamizu, N. (2011) Assessing the Removal Potential of Soil Aquifer Treatment System (Soil Column) for Endotoxin. Journal of Environmental Monitoring, 13, 1716-1722. http://dx.doi.org/10.1039/c1em10071h

[21] Guizani, M. and Funamizu, N. (2012) Microfiltration, Nano-Filtration and Reverse Osmosis for the Removal of Toxins (LPS Endotoxin) from Wastewater. Journal of Membrane Science and Technology, 2, 118-123.

[22] Boes, M., Prodeus, A.P., Schmidt, T., Carroll, M.C. and Chen, J. (1998) A Critical Role of Natural Immunoglobulin M in Immediate Defense against Systemic Bacterial Infection. The Journal of Experimental Medicine, 188, 2381-2386. http://dx.doi.org/10.1084/jem.188.12.2381 
[23] Sharma, S.K. (1986) Endotoxin Detection and Elimination in Biotechnology. Biotechnology and Applied Biochemistry, 8, 5-22.

[24] Reichelt, P., Schwarz, C. and Donzeau, M. (2006) Single Step Protocol to Purify Recombinant Proteins with Low Endotoxin Contents. Protein Expression and Purification, 46, 483-488. http://dx.doi.org/10.1016/j.pep.2005.09.027

[25] Guizani, M. and Funamizu, N. (2014) Endotoxin Occurrence in Raw and Reclaimed Wastewater. Journal of Water Resource and Protection, 6, 688-695. http://dx.doi.org/10.4236/jwarp.2014.67066

[26] Sweadner, K.J., Forte, M. and Nelsen, L.L. (1977) Filtration Removal of Endotoxin (Pyrogens) in Solution in Different States of Aggregation. Applied and Environmental Microbiology, 34, 382-385.

[27] Kimura, K., Hane, Y., Watanabe, Y., Amy, G. and Ohkuma, N. (2004) Irreversible Membrane Fouling during Ultrafiltration of Surface Water. Water Research, 38, 3431-3441. http://dx.doi.org/10.1016/j.watres.2004.05.007

[28] Magalhães, P.O., Lopes, A.M., Mazzola, P.G., Rangel-Yagui, C., Penna, T.C. and Pessoa Jr., A. (2007) Methods of Endotoxin Removal from Biological Preparations: A Review. Journal of Pharmacy \& Pharmaceutical Sciences, 10, 388-404.

[29] Guizani, M., Dhahbi, M. and Funamizu, N. (2010) Characterization of Endotoxic Indicative Organic Matter (2-Keto3deoxyoctulosonic Acid) in Raw and Biologically Treated Domestic Wastewater. Water Research, 45, 155-162. http://dx.doi.org/10.1016/j.watres.2010.08.013

[30] Darkow, R., Groth, T., Albrecht, W., Lutzow, K. and Paul, D. (1999) Functionalized Nanoparticles for Endotoxin Binding in Aqueous Solutions. Biomaterials, 20, 1277-1283. http://dx.doi.org/10.1016/S0142-9612(99)00022-8

[31] Rietschel, E.T., Brade, H., Brade, L., Brandenburg, K., Schade, U., Seydel, U., Zähringer, U., Galanos, C., Lüderitz, O., Westphal, O., Labischinski, H., Kusumoto, S. and Shiba, T. (1987) Lipid A, the Endotoxic Center of Bacterial Lipopolysaccharides: Relation of Chemical Structure to Biological Activity. Progress in Clinical \& Biological Research, 231, 25-23.

[32] Vaara, M. and Nurminen, M. (1999) Outer Membrane Permeability Barrier in Escherichia Coli Mutants That Are Defective in the Late Acyltransferases of Lipid A Biosynthesis. Antimicrobial Agents and Chemotherapy, 43, 1459-1462.

[33] Petsch, D. and Anspach, F.B. (2000) Endotoxin Removal from Protein Solutions. Journal of Biotechnology, 76, 97119. http://dx.doi.org/10.1016/S0168-1656(99)00185-6

[34] HACH (2011) Organic Carbon, Total, Direct Method (Method 10173). 6th Edition, HACH Water Analysis Book.

[35] Srinivasan, P.T., Viraraghavan, T. and Subramanian, K.S. (1999) Aluminium in Drinking Water: An Overview. Water $S A, 25,47-55$.

[36] Gregory, J. and Duan, J. (2001) Hydrolyzing Metal Salts as Coagulants. Pure and Applied Chemistry, 73, $2017-2026$. http://dx.doi.org/10.1351/pac200173122017

[37] Rezaee, A., Ghanizadeh, G.H., Yazdanbakhsh, A.R., Behzadiannejad, G.H., Ghaneian, M.T., Siyadat, S.D. and Hajizadeh, E. (2008) Removal of Endotoxin in Water Using Ozonation Process. Australian Journal of Basic and Applied Sciences, 2, 495-499.

[38] Amirtharajah, A. and Jones, S.C. (2000) Drinking Water Treatment. The Engineering Handbook. CRC Press Llc., Boca Raton.

[39] Kan, C., Chuang, C. and Pan, J.R. (2002) Time Requirement for Rapid Mixing in Coagulation. Colloids and Surfaces A: Physicochemical and Engineering Aspects, 203, 1-9. http://dx.doi.org/10.1016/S0927-7757(01)01095-0

[40] Chakraborti, R.K., Gardner, K.H., Atkinson, J.F. and van Benschoten, J.E. (2003) Changes in Fractal Dimension during Aggregation. Water Research, 37, 873-883. http://dx.doi.org/10.1016/S0043-1354(02)00379-2

[41] Myers, R.H., Khuri, A.I. and Carter, W.H. (1989) Response Surface Methodology, 1966-1988. Technometrics, 31, 137-157. http://dx.doi.org/10.2307/1268813 


\section{Submit or recommend next manuscript to SCIRP and we will provide best service for you:}

Accepting pre-submission inquiries through Email, Facebook, LinkedIn, Twitter, etc.

A wide selection of journals (inclusive of 9 subjects, more than 200 journals)

Providing 24-hour high-quality service

User-friendly online submission system

Fair and swift peer-review system

Efficient typesetting and proofreading procedure

Display of the result of downloads and visits, as well as the number of cited articles

Maximum dissemination of your research work

Submit your manuscript at: http://papersubmission.scirp.org/ 